\title{
Nísia Floresta e mulheres de letras no Rio Grande do Norte: pioneiras na luta pela cidadania
}

Nísia Floresta: vida e obra.

UMA DUARTE, Constância .

Natal: Ed. da UFRN, 1995. 365 p.

A educação feminina no Brasil do século XIX, segundo diversostestemunhos, muito deixa va a desejar. Os viajantes Kidder e Fletcher, aqui presentes em 1851, afirmavam que, naquele momento, não teria m a s mulheres bra sileira suma base de conhecimentos variados para tomar agradável e instrutiva a sua palestra, embora taga relassem insignific âncias de modo sempre a gradá vel. ${ }^{1}$ Por outro lado, eles admitiam excelências de algumas escolas que estavam a pa recendo, mas das qua is os pa is retira va m suas filhas ao completarem 13 ou 14 anos, considerando-as preparadas para a vida, portanto a ptas a o casamento, convic tos de esta ser a opção de futuro mais adequada às mulheres. Ta is depoimentos e a titudes revela $m o$ descaso quanto às capacidades e potencialidades dasmulherese pareciam, a rigor, desconhecera vasta e varia da produção literária feminina do período. Não considera va mo esforço de muitas delas para transpor os obstáculos e vencer os preconceitos e a ridicula riza ção pública por ousarem penetrar em um espaço considera do de exclusivida de masculina. Como em outras partes do mundo, as mulheres que perseguiam tal propósito eram alvo de zombaria e severa crítica, o que justific aria que boa parte delas temesse a publicação de seus textos, perdendo-se porisso muitos deles, enquanto que outras, para terem seus textos publicados, a dotavam pseudônimos masculinos, a exemplo de George Sand, George Eliot, Currer Bell e Otto Stern.

Rec entemente, pesquisa doras feministas historia doras, litera tas, crític as literárias - têm se dedicado a buscar pistas, indícios que thes

\author{
Literatura feminina do Rio \\ Grande do Norte: de Nísia \\ Floresta a Zla Mamede.
}

LIMA DUARTE, Constância; MACEDO, Diva Maria Cunha P. de.

Natal: Sebo Vermelho/UnP, 2001. 232 p.

permita $m$ transporas inúmeras dific uld a des pa ra recuperar essa produção inédita, a usente da historiografia literária. Dentre essas pioneiras, encontra-se Constância Lima Duarte, que empreendeu uma exc elente investigação sobre a intelectual e literata Nísia Floresta, hoje considerada a primeira feminista brasileira, cuja vida e obra mantiveram-se praticamente desconhecidas durante muitos anos. ${ }^{2}$ Para 0 resgate da obra dessa importante figura, Constância percorreu arquivos e bibliotecas do nordeste a o sul do país, a ssim como no exterior Portugal, França e Itália -, recolhendo marcas e informações que the permitissem reconstruir a trajetória da personagem em foco.

Não é pequeno, portanto, o mérito de Constância que, através de um trabalho de fôlego, traz à cena essa personagem de signific a tiva a tua ç ão política, social e literária em sua época. Como esclarece Constância, algo que emergiu com toda força em seu objeto de investigação foi a riqueza da personalidade de Nísia, uma mulher de fibra que nasceu em 1810, em uma pequena localidade - Papari (hoje Nísia Floresta) - do Rio Grande do Norte, estado do Nordeste do Brasil, onde viveu os primeiros a nos de sua existência. Casada aos 13 anos, abandonou o marido alguns meses depois, voltando a residir com os pais. Ma is tarde, em 1828, ena mora-se de um jovem acadêmico, com quem passa a residir, e do qual terá dois filhos. Em decorrência de tais fatos, foi vítima de campanha caluniosa, especialmente por parte de seus conterrâneos. Nísia foi, talvez, uma das primeiras a romper com os preconceitos que cercavam as mulheres no país. Foi uma das 
primeirasta mbém a colaborarem joma is, a partir de 1830, em Recife, publicando ma is tarde contos, poesias, novelas e ensa ios em periódic os do Rio de Janeiro. Envolveu-se plenamente com as questões cultura is de seu tempo, manifestandoas em sua militância que se abria em diversas vertentes. Tal fa to, porém, não se expressaria de forma compartimentada, mas como peças complementares de um mesmo plano de ação no conjunto de sua obra, sempre imbuída do propósito de formare modific ar consciências.

Em Nísia Floresta: vida e obra, diante das idéias inova doras, e mesmo revolucionárias, assim como dos aspectos de exceção presentes no comportamento de Nísia Floresta, segundo sua opinião, e porrazões didáticas, Constância a firma ter sido compelida a dividir a obra da escritora em cinco partes. No primeiro ca pítulo, a presenta a biobibliografia da personagem, buscando, muito adequadamente, situá -la no seu contexto histórico e cultural. Os textos que tratam das diversas vertentes de sua militância, como o indianismo, o nacionalismo, a questão da escravidão, o feminismo e o positivismo, são estudados no segundo capítulo. Neste, no que tange ao feminismo, a pesquisadora realça a intenção de Nísia de conscientizar a s mulherese os homens contemporâneos sobre os respectivos papéis na sociedade e a necessidade de mudanças nos padrões de comportamento. Aponta, dentre as obras consultadas, a importância de seu primeiro livro - Direitos das mulheres e injustiças dos homens -, public ado em 1832, e inspirado na obra de Mary Woolstonecraft Vindications of the rights of woman, em que Nísia enfatiza os direitos das mulheres à instrução e ao trabalho, exigindo o reconhecimento à inteligência e o respeito ao papel das mulheres na sociedade. Quanto ao positivismo, o fa to é rela tivizado por Constância, que se propõe a mostrarque, longe de aderira ele, Nísia se a propriava a penas dosaspectosque enfatiza vam a elevação do sta tus feminino, não levando em conta a posição subordina da a que a doutrina condicionava a mulher, quando priorizava a função de mãe e esposa em detrimento das demais. De certo modo, essa a mbigüidade denota um paradoxo na obra de Nísia.

Constância reserva o terceiro capítulo para focalizar a educação feminina, pelo vulto assumid o no espectro de preocupações de Nísia. Mostra como, na perspectiva de muitos dos intelectuais da época, a educação feminina é ressaltada como base para o progresso da sociedade. Em duas de suas obras Nísia dedica- se à questão: Conselhos à minha filha, de 1842 , e Opúsculo humanitário (Ensa io sobre educação), de 1853. Seu interesse por essa problemática levou-a a fundarem 1838, e dirigir durante anos, um colégio para meninas no Rio de Janeiro - o Colégio Augusto -, cujo nível competia em qualidade com os melhores ali existentes, via de regra, dirigidos por estrangeiras. Observa Constância que, nos joma is da época, ao lado doselogios à serieda de do trabalho desenvolvido no colégio, encontram-se também críticas à diretora por ousar privilegiar o ensino de línguas, em prejuízo dos traba lhos manua is, o que confima um dos a spec tos subversivos da a tua ção de Nísia Floresta.

As viagens de Nísia são a nalisadas no capítulo seguinte, cabendo esclarecer que ela embarcou com a filha para a Europa em 1849, onde residiu por 28 anos e, embora transitasse porvários países, como Portugal, Ing la terra e Itália, fixou-se na França. Relacionou-se com intelectua is como Augusto Comte e alguns dos grandes escritores da época. De suas viagens resultaram dois livros: Itineraire d'un voyage en Allemagne, de 1857, e Trois ans en Italie, suivis d'un voyage en Grèce, publicados em francês. ${ }^{3}$ Neste último, detém-se na questão da unific ação italiana, revelando sua admiração por líderes como Garibaldi, com quem se correspondeu durante algum tempo. Ainda em Paris, public ou o ensa io O Brasil, em 1871, buscando divulgar fatos e combater preconceitos que predominavam na Europa acerca do seu país. Nísia Floresta faleceu em Rouen, na França, em 1885.

Constância Lima Duarte, unindo paixão e rigor acadêmico, a o concorrer para a reabilitação e justa consa gração de Nísia Floresta, que por sua vida e obra constitui um exemplo de insubmissão aos preconceitos de seu tempo, contribui signific a tivamente para ma is um passo no esforço de dar visibilidade a uma história por longo tempo marcada pela opacidade: a luta das mulheres pela a quisição de direitos e plena cidadania.

Além dessa obra, Constância Lima Duarte, enquanto professora na Universidade Federal do Rio Grande do Norte, dedicou-se, juntamente com outra pesquisadora, a professora Diva Cunha Pereira de Macedo, a esquadrinhar a produção literária de mulheres naquele estado, desde o século XIX a té os primeiros a nos do XX. Iniciaram o trabalho em 1992, percorrendo bibliotecas e a rquivos do estado e entrando em conta to com estudiosos e intelectua is do Rio Grande do Norte e de outros estados, a tra vés de cartase de visitas pessoais. Tinham como objetivo encontra rlivrose 
manuscritos, buscar informações sobre intercâmbios mantidos por a quelas escritoras e procurar vestígios de uma imprensa feminina preocupada em incentivare divulgar a literatura feita por mulheres. Nesse particular, localizaram na Biblioteca Nacional, no Rio de Janeiro, oito números da revista Via Láctea (1914-1915), edita da por Carolina e Palmira Wanderley, assim como uma coleção quase completa de um jomal caprichosamente manuscrito - Esperança - que sobreviveu de março de 1903 a outubro de 1909, sob responsabilidade de Dolores Cavalcante e Izaura Ca milho.

A pesquisa resultou no signific a tivo número de 99 nomes de mulheres nascidas entre 1810 e 1927, das quais selecionaram 25 nomes para comporem a antologia - Literatura Feminina do Rio Grande do Norte: de Nísia Floresta a Zila Mamede - organizada por elas. O grosso da produção a presentada constitui-se de poemas, gênero à época considera do ma is a dequado às mulheres, embora não faltassem aquelas que enveredavam pela dramaturgia e pela na rrativa, masque pemaneceram no a nonimato. Lembram as organizadoras da necessidade de serem consideradas, na análise de poemasou livros das primeiras literatas, as limitações a que eram submetidas as mulheres em termos de movimentação, inic iativas, controle das leituras, sem deixar de levar em conta o tardio acesso delas a os cursos universitá rios. Ma nifesta $m$ a inda a surpresa pela constatação de que muitas dessas obras, a pesar dos obstáculos socia is, cultura is e mora is a que estavam sujeitas suas autoras, a presentava $m$ idêntico va lor literário a o daquelas a ssina das por seus pares masc ulinos.

Finalmente acentue-se, mais uma vez, a relevância dessas iniciativas para questionar a suposta sujeição das mulheres bra sileirasa valores impostos, a restrição de sua a tua ção a o espaço doméstico e a sua a lienação quanto à realidade política, social e cultural do país. O trabalho de Constância, a lém da importante contribuição à literatura pelo resgate de escritoras, a té então desconhecidas, permite uma melhor compreensão da evolução históric a das lutas das mulheres que, muitas vezes, tiveram de recorrer a 'brechas' para avançarem seus ideais. Dessa maneira, entende-se como algumas, talvez ma is ousa dasou ma is fa vorecidas pelas contingências, conseguiram impor-se "esc revendo livros, criando escolas e jornais, fazendo conferências", não como um escape a o confinamento em que vivia a maioria, mas sim por dever de uma cidadania e de uma consciência profissional que as impelia a lutarporuma plena participação de homense mulheres de todas as classes, raças e etnias; enfim, por uma sociedade mais justa.

\section{Notas}

${ }^{1}$ Da niel KIDDER e J a mes FLETC HER, 1941, p. 121.

20 trabalho constituiu-se, originalmente, em tese de doutorado, apresentada à Universidade de São Paulo em 1991.

${ }^{3}$ O primeiro foi traduzido para o português em 1982 e reeditado em 1998, e o segundo, recentemente traduzido e publicado em Natal pelo professor Francisc 0 das Chagas Pereira.

\section{Referência bibliográfica}

KIDDER, Daniel P.; FLETCHER, James C. O Brasil e os brasileiros. São Paulo: Cia. Editora Nacional, 1941.

Rachel Soihet

Universida de Federal Fluminense 